\title{
Impacts of Global Warming on Energy Use for Heating and Cooling with Full Rebound Effects in Switzerland ${ }^{a}$
}

\author{
Camille Gonseth ${ }^{b}$ Philippe Thalmann $^{c}$ and Marc Vielle ${ }^{d}$
}

JEL-Classification: C63, Q41, Q54

Keywords: climate change, heating, cooling, computable general equilibrium model, Switzerland, adaptation, rebound effect

\section{SUMMARY}

This paper analyzes the impacts of the modified needs for space heating and cooling due to global warming on the quantities of energy used for space conditioning and overall. It thereby estimates direct and total rebound effects, the latter including changes in consumption and production triggered by changes in energy needs for space conditioning by households, services and industry. A computable general equilibrium model is used to simulate a range of climate and impacts scenarios for Switzerland over the period 2010-2060. We find significant welfare gains from reduced heating needs, exceeding largely the costs of the additional electricity needed for cooling. We also find large rebound effects. For instance, while the climate scenario A1B would allow households to reduce their consumption of fossil energy for room heating by $15.9 \%$, actual reductions are only $10.4 \%$, which implies a direct rebound effect of $35 \%$. Economy wide, fossil energy consumption could decrease by $4.3 \%$ but does so only by $2.7 \%$, which represents a total rebound effect of $37 \%$.

a Acknowledgements: The research leading to these results has received funding from the Swiss Federal Office for the Environment. We would like to thank Anne-Kathrin Faust, Pamela Koellner-Heck and Roland Hohmann for their helpful comments and suggestions. We would also like to thank Florent Baume for his research assistance. Finally, we are grateful to the participants of the ETH CEPE lunch seminar in Energy and of the GTAP 2012 Conference for their comments and suggestions. Two anonymous reviewers are also gratefully thanked for their valuable comments and suggestions.

b LEURE, Ecole Polytechnique Fédérale de Lausanne, Lausanne, Switzerland. Email: cgonseth78@gmail.com.

c LEURE, Ecole Polytechnique Fédérale de Lausanne, Lausanne, Switzerland. Email: philippe.thalmann@epfl.ch.

d LEURE, Ecole Polytechnique Fédérale de Lausanne, Lausanne, Switzerland. Email: marc.vielle@epfl.ch. 


\section{Introduction}

With the certainty that some amount of climatic warming will occur, the focus in climate change policy has moved gradually from mitigation to impact assessment and adaptation issues. Our research is in line with this evolution because our aim is to contribute to the estimation of the impacts of climate change on Swiss energy demand. At the worldwide level, the energy sector is expected to be impacted by climate change through several channels, among which: (i) hydropower will be affected by changes in runoff and river flows (LeHner, Czisch, and Vassolo, 2005; Hamududu and Killingtveit, 2012); (ii) changes in cooling efficiency of thermal power plants will impact their availability and efficiency (Linnerud, Mideksa, and Eskeland, 2011; Rübbelke and VöGele, 2011); (iii) energy transport infrastructure will become more vulnerable from extreme climate events (CraIG, 2011); (iv) energy demand will be impacted through changes in space heating and cooling needs (AuffHammer and Mansur, 2014; Ciscar and Dowling, 2014; De Cian, Lanzi, and Roson, 2013). Our contribution focuses on this last effect.

In Switzerland, the energy sector is expected to be one of the most affected by climate change along with the agriculture, tourism, water distribution, health, insurances, and infrastructures sectors (OCCC and ProClim, 2007). A few studies have already analyzed the potential impacts of climate change on Swiss energy demand (Frank, 2005; Christenson, Manz, and Gyalistras, 2006; Aebischer et al., 2007), and their results show that a warming climate could reduce the energy demand for heating, while at the same time also increase the energy demand for cooling. However, they lack an economic perspective and do not use the most up-to-date climatic scenarios for Switzerland.

The aim of this paper is to estimate the economic and welfare impacts of climate change driven temperature changes that affect space heating and cooling. To this end, it uses a computable general equilibrium (CGE) model, which allows it to take into account induced changes in prices and incomes and their indirect effects on energy demand. Several papers have already studied with a CGE model the impact of climate change in the energy sector. CISCAR and Dow LING (2014) reviewed the literature on the integrated modeling of climate impacts on the energy sectors, including four CGE models: ENVISAGE, ICES, GRACE and IGEM. One of the first significant contributions in this area was by Roson, Bosello, and Cian (2007). They used the GTAP-E CGE model in which the impact of temperature changes is introduced through an exogenous shock on the structure of demand. They found that higher temperatures bring about lower consumption of most energy goods except electricity. The same 
methodology is applied by the OECD with the ENV-Linkages model (OECD, 2015). It concluded that temperature increases will lead to reduced household demand for heating fuels in all regions. In contrast, the household sector is projected to increase its electricity demand in only half of the 25 regions represented in ENV-Linkages. In the other half of the regions, electricity demand decreases because the fall of electricity used for heating is not offset by an increase in demand for space cooling. In this paper we propose to apply a different methodology to integrate the effects of temperature changes on energy demand. We use the CGE model GEMINI-E3 (Bernard and Vielle, 2008). So far, it has been largely used to derive general equilibrium costs and benefits of European and Swiss energy and climate policies. The model has recently been improved in order to integrate and assess the impacts of climate change on the economy and to address adaptation capacities against a warming climate (LABRIET et al., 2015; Faust, Gonseth, and Vielle, 2015; Joshi et al., 2016).

The paper is structured as follows: Section 2 presents the main features of the GEMINI-E3 model, in particular the modelling of energy demand and supply. Then, we describe the methodology used to compute the impacts of climate change on heating and cooling needs and how they are integrated into the equations of the model. Section 3 presents the climate scenarios that are used to derive the ex-ante impacts on heating and cooling demands. Then, we evaluate them for the period of 2010-2060. In Section 4, we introduce these impacts into the GEMINI-E3 model and investigate their economic repercussions. The final section presents the conclusions of this study.

\section{The GEMINI-E3 Model}

\subsection{Overview of GEMINI-E3}

GEMINI-E $3^{1}$ is a multi-country, multi-sector, recursive computable general equilibrium model comparable to many other CGE models (EPPA, OECD Env-Linkage, etc.) built and implemented by other modeling teams and institutions, and shares the same long experience in the design of this class of economic models. The standard model is based on the assumption of total flexibility in all markets, both the macroeconomic markets such as the capital and the exchange markets

1 All information about the model can be found at http://gemini-e3.epfl.ch/, including its complete description.

Swiss Journal of Economics and Statistics, 2017, Vol. 153 (4) 
Table 1: Industrial Classification

\begin{tabular}{|rl|ll}
\hline 1 & Coal & 15 & Paper products and publishing \\
\hline 2 & Crude oil & 16 & Land transport \\
3 & Natural gas & 17 & Sea transport \\
4 & Petroleum products & 18 & Air transport \\
\hline 5 & Electricity & 19 & Consuming goods \\
\hline 6 & Crop & 20 & Equipment goods \\
\hline 7 & Milk & 21 & Winter overnight tourism \\
\hline 8 & Animal products & 22 & One-day winter tourism \\
\hline 9 & Vegetables & 23 & Other forms of tourism \\
\hline 10 & Other agricultural products & 24 & Insurance and pension funding \\
11 & Forestry & 25 & Health and social work \\
\hline 12 & Mineral products & 26 & Services \\
13 & Chemical & 27 & Dwellings \\
\hline 14 & Metal and metal products & 28 & Water \\
\hline
\end{tabular}

(with the associated prices being the real rate of interest and the real exchange rate, which are endogenous), and the microeconomic or sector markets (goods, factors of production). The model is built on the Swiss input-output table (NATHANI et al., 2011) and the GTAP database (Dimaranan, 2006) for the other countries.

For each sector, the model computes the demand for its production on the basis of household consumption, government consumption, exports, investment, and intermediate uses. Total demand is then divided between domestic production and imports, using the Armington assumption (ARMINGTON, 1969). Under this convention a domestic product is distinguished from an imported product of the same industry. Production technologies are described by nested Constant Elasticity of Substitution (CES) functions.

Time periods are linked through endogenous real interest rates that equate savings and investment. Capital is not mobile across regions. National and regional models are linked by endogenous real exchange rates resulting from constraints on foreign trade deficits or surpluses.

The sectoral structure of the model has been extended for Switzerland in order to assess the economic impact of climate change on particularly sensitive sectors, such as tourism, agriculture and water distribution. The new structure used in this study comprises 28 sectors listed in Table 1 . The model describes five energy 
goods and sectors: coal, crude oil, natural gas, petroleum products and electricity. With regard to the regions represented by this model, we use an aggregated version of GEMINI-E3 that describes six countries/regions: Switzerland, the European Union, the United States of America, other developed countries, BRIC (Brazil, Russia, India and China), and the rest of the world.

\subsection{Energy Demand and Supply in GEMINI-E3}

The domestic energy demand is equal to the sum of energy consumed by firms as an intermediate input and of energy consumed by households as a final product. The production structure of the industrial and service sectors is shown in Figure 1.

Figure 1: Nested CES Production Structure of Industrial and Service Sectors

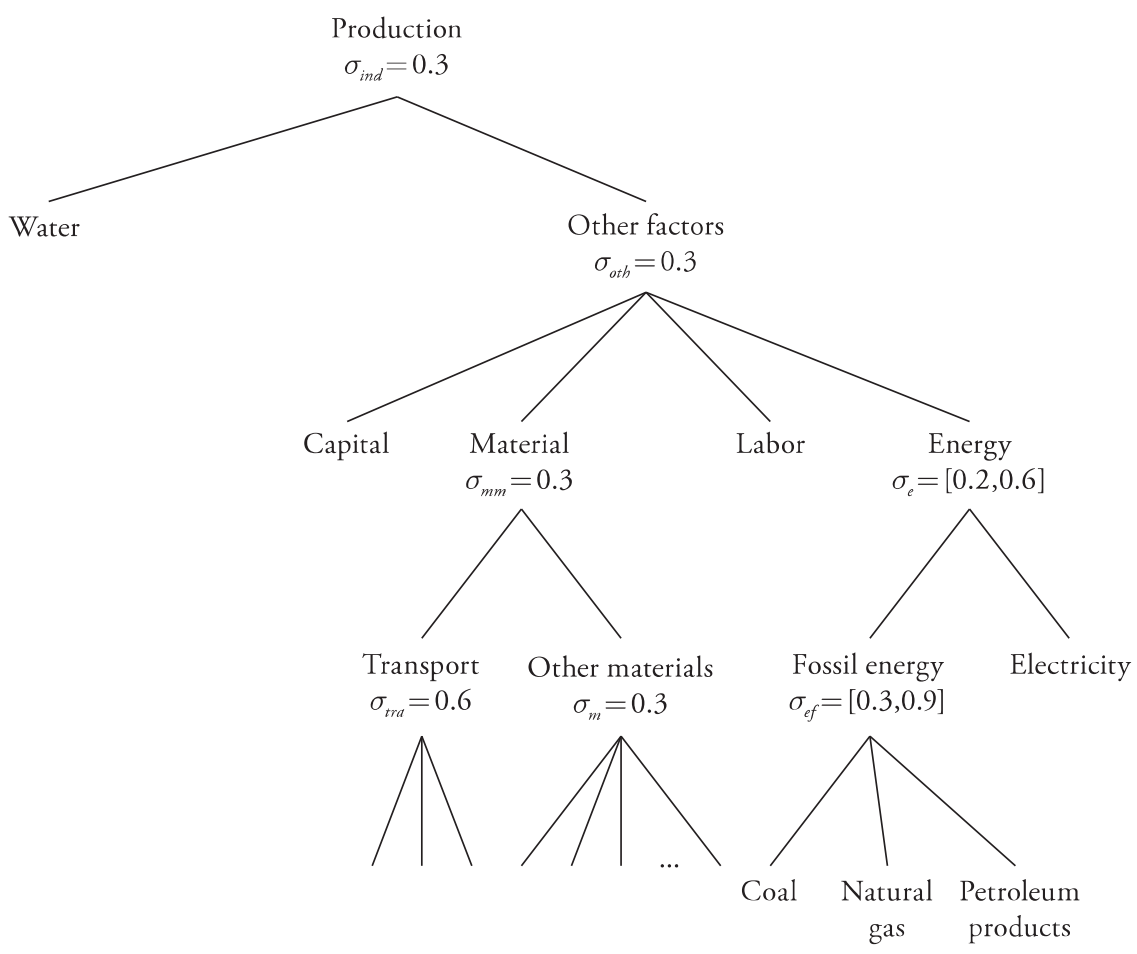

The representative consumer maximizes a nested CES utility function, described in Figure 2. Energy consumption is divided between transportation and housing purposes. In each nest, energy can be substituted by spending more on capital 
goods, cars in the first case and shelter in the second one, in other words, by purchasing more energy-efficient but also more expensive cars and housing units.

Considering that in Switzerland coal, natural gas and crude oil are imported, we only present the modeling of electricity generation. In this version of GEMINI-E3, electricity production is represented by a nested CES function, which, aside from fossil fuels, nuclear and hydraulic plants, includes the new capacities installed in the renewable technologies. Power generation is then separated from the other activities (transmission and distribution) that appear through their factors of production at the top of the nesting structure. Power generation involves only two factors of production: capital and fuel (only capital for renewables) $)^{2}$. With this nesting structure, it is possible to better integrate the power generation portfolio and to represent inter-fuel substitutability, as well as substitutability between fossil and renewable power generation (WING, 2006).

\subsection{Energy Demand for Heating}

An important step for calibration consists in defining the amounts of energy consumed for heating purposes in the different sectors of the economy, as well as the share of each source of energy in these consumptions ${ }^{3}$. Heating represents a central share of the overall household energy consumption for housing $(72.4 \%)$. This share is also high in the sector "Services and Agriculture" (55.0\%), whereas it is much lower in the industry sector (14.4\%). The overall energy need for heating is covered in its majority by imported fossil fuels (86.1\%). In 2010, oil and natural gas represent respectively $54 \%$ and $21 \%$ of energy used for heating by households (Prognos, 2012). The remaining part is covered by wood (10\%), electricity ( $8 \%)$, heat pumps ( $4 \%)$ and distributed heat $(3 \%)$.

The climate is well-known to be one of the main determinants of the amount of energy demanded for heating at a given location. Quite logically, a warmer climate is expected to reduce this demand, but one has to quantify this effect based on climatic scenarios. The comparison of energy needs for heating with and without climate change is often carried out using a climatic index based on average daily temperatures, the heating degree-days (Christenson, ManZ, and

2 Labor in the generation activity is low compared to labor in the other activities (transport, distribution) and of a similar relative size for all plants. It is thus represented as a common factor.

3 For Switzerland, three aggregate sectors and the year 2001, this information is available in (Kirchner et al., 2010). Unless otherwise specified, the paragraph's figures are drawn from this source. 


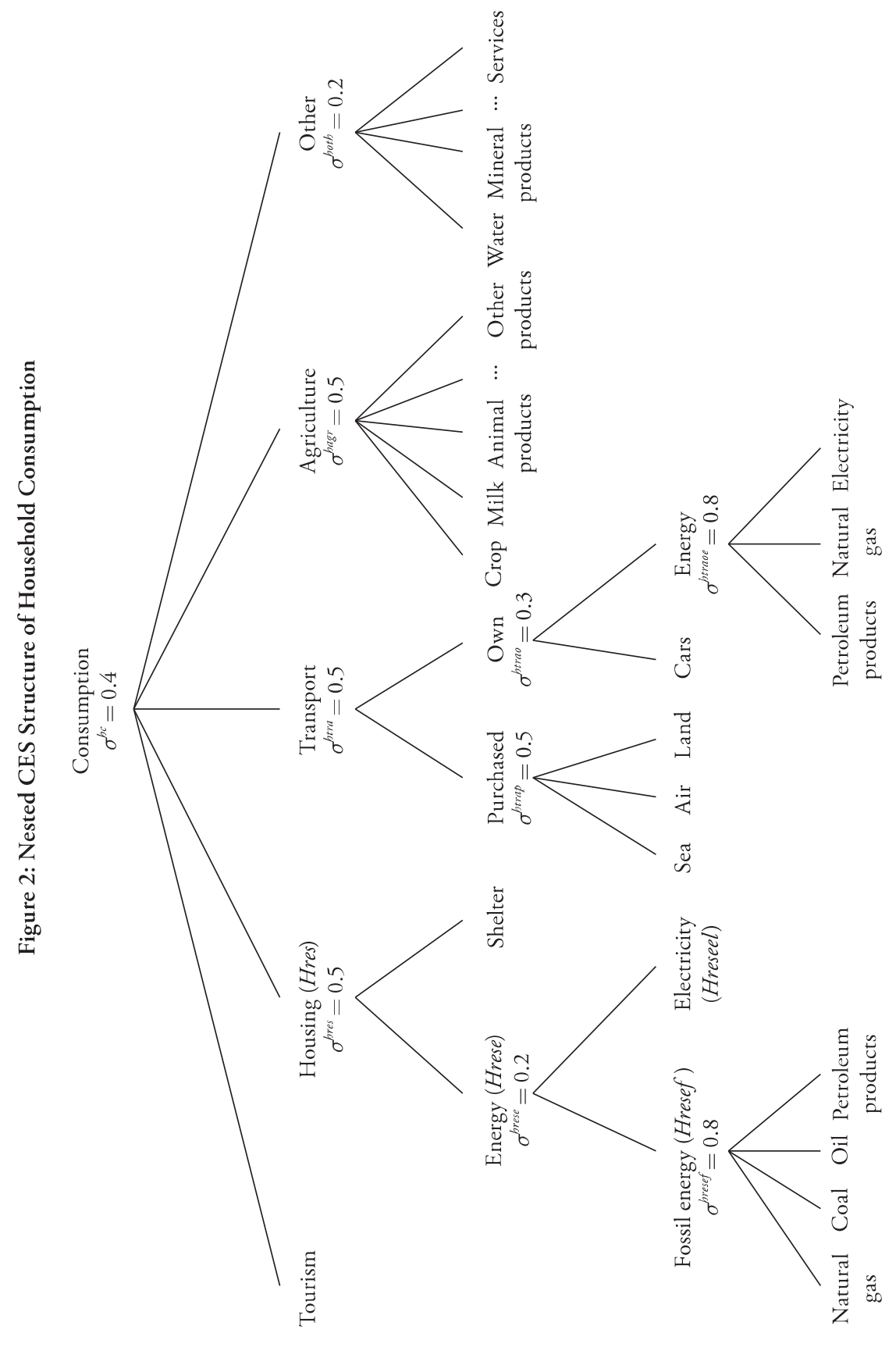

Swiss Journal of Economics and Statistics, 2017, Vol. 153 (4) 
Gyalistras, 2006). Following recommendations of the Swiss professional association of engineers and architects, we compute the heating degree-days (HDD) using equation 1 .

$$
H D D\left(\theta^{*}, \theta_{t h}\right)=\sum_{k=1}^{365} m_{k} \cdot\left(\theta^{*}-\theta_{k}\right)
$$

with $m_{k}=1$ if $\theta_{k} \leq \theta_{t h}$ and $m_{k}=0$ otherwise.

In this equation $\theta^{*}$ is the target interior temperature, $\theta_{k}$ is the average daily temperature for day $k$ and $\theta_{t h}$ is the threshold outside temperature under which heating becomes necessary. The formula for HDD computes and sums daily differences between the inside and outside temperatures, whenever the daily mean temperature is lower than the threshold temperature, which reflects the quality of housing insulation. The better the insulation of buildings, the lower the value of the threshold temperature. Values of the parameters of equation 1 that are commonly used for Switzerland are the following (Christenson, Manz, and Gyalistras, 2006; Kirchner et al., 2010): $\theta^{*}=20^{\circ}$ and $\theta_{t h} \in\left\{8,10,12^{\circ}\right\}$. To derive our ex-ante impact, we assume that the energy demand for heating is proportional to the value of HDD.

\subsection{Energy Demand for Cooling}

The degree-days method can also be used to assess the quantity of energy required in a given climate for cooling. The ASHRAE ${ }^{4}$ formula for cooling degree-days (CDD), similar to the one used to compute HDD, is given below (HowelL, SAUer, and Coad, 2005).

$$
C D D\left(\theta_{b p}\right)=\sum_{k=1}^{365} n_{k} \cdot\left(\theta_{k}-\theta_{b p}\right)
$$

with $n_{k}=1$ if $\theta_{k} \geq \theta_{b p}$ and $n_{k}=0$ otherwise.

In this equation, $\theta_{k}$ and $\theta_{b p}$ are respectively the average daily temperature for day $k$ and the balance point temperature above which cooling becomes necessary. The formula for CDD first determines days for which cooling is necessary, based on the threshold temperature $\theta_{b p}$, and it then sums the differences between outside and threshold temperatures across these days. A standard value of $\theta_{b p}$ is

4 ASHRAE is the abbreviation for the American Society of Heating, Refrigerating and AirConditioning Engineers. 
not available for Switzerland, so we will use $\theta_{b p}=18.3^{\circ}$, which has been used in the Swiss context (Christenson, Manz, and Gyalistras, 2006; Kirchner et al., 2010). To link CDD values to energy consumption for cooling, we refer to a linear relationship that was estimated using data on a sample of cooled office buildings located in different European countries (AEBISCHER et al., 2007).

$$
D_{t}^{\text {spec }}=\frac{12.7+0.103 \cdot C D D_{t}}{\left(1+\tau_{\text {cooling }}\right)^{t}}
$$

Here $D_{t}^{\text {spec }}$ is the specific electricity consumption for cooling given in $\mathrm{KWh} / \mathrm{m}_{c}^{2}$ with $m_{c}^{2}$ as the fully cooled surface for period $t$ and $\tau_{\text {cooling }}$ is a technical progress that assumes an autonomous annual reduction of the specific energy requirements by $0.5 \%$ per year.

Equation 3 provides the annual value of electricity consumption for a one square meter of a fully cooled surface as a function of $\mathrm{CDD}^{5}$. Because of the constant term, it is worth noting that the percentage change in specific electricity consumption is lower than the percentage change in CDD.

Another challenging point with cooling is that the proportion of cooled surfaces is expected to increase in the future. Due to the constant modernization of the building stock (especially through insulation), we expect the thermal comfort inside the buildings to worsen on hot days (overheating risks) as explained in AEBIsCHER et al. (2007). Other trends such as growing glass surfaces on the facades and the denser occupation of the workspace triggered by higher costs augment these overheating risks. The trend towards an increased proportion of cooled surfaces should be reinforced by climate change. For the service sector, AeBischer et al. (2007) developed a set of assumptions regarding this evolution. They are summarized in Table 2 for their "no climate change scenario". Values for the period 2050-2060 are obtained by linear extrapolation from their original data.

Aebischer et al. (2007) applied some corrective factors to the values displayed in Table 2 when accounting for climate change ${ }^{6}$. By 2035, they assume that half of the non-cooled surfaces under the scenario "no climate change" will be partially cooled while half of the partially cooled surfaces will be fully cooled. We

5 For partially cooled surfaces, the relationship needs to be corrected by scaling down the specific electricity consumption by a factor of 4 (Aebischer et al., 2007)

6 Their climate change scenario for Switzerland is an intermediate one that predicts a $2^{\circ} \mathrm{C}$ increase in temperature during summer months and a $1^{\circ} \mathrm{C}$ increase during the rest of the year over the time span 1990-2035.

Swiss Journal of Economics and Statistics, 2017, Vol. 153 (4) 
Table 2: Cooled Surfaces Expressed as Percentages of Total Surfaces in the Service Sector under a Scenario with no Climate Change (Source: Aebischer et al., 2007)

\begin{tabular}{lccccccc}
\hline & 2000 & 2005 & 2015 & 2025 & 2035 & 2050 & 2060 \\
\hline Not cooled & $61 \%$ & $59 \%$ & $54 \%$ & $49 \%$ & $44 \%$ & $36 \%$ & $30 \%$ \\
Partially cooled & $20 \%$ & $22 \%$ & $25 \%$ & $27 \%$ & $30 \%$ & $36 \%$ & $40 \%$ \\
Fully cooled & $19 \%$ & $19 \%$ & $21 \%$ & $23 \%$ & $25 \%$ & $28 \%$ & $30 \%$ \\
\hline
\end{tabular}

apply these corrections to the last two columns of Table 2 in order to obtain estimates of the proportion of partially and fully cooled surfaces in the service sector for 2050 and 2060 under a climate change scenario. In this scenario, $50 \%$ of surfaces will be fully cooled and $35 \%$ partially cooled in 2060 . The electricity used for cooling in the service sector is then estimated by the following equation:

$$
\text { Elec }_{t}=D_{t}^{\text {spec }} \cdot \text { Surface }_{t} \cdot\left(\alpha_{t}^{\text {frool }}+\frac{\alpha_{t}^{\text {pcool }}}{4}\right),
$$

where Surface, $_{t}$ represents the overall surface in the service sector, $\alpha_{t}^{\text {fiool }}$ the proportion of surfaces that are fully cooled and $\alpha_{t}^{\text {pcool }}$ the one that are partly cooled.

According to our estimates, surfaces in the service sector amounted to 60 million $\mathrm{m}^{2}$ in 2000 compared to 250 million $\mathrm{m}^{2}$ in the housing sector. Assuming that these surfaces will grow at the same rate as their respective sector, we estimate future surfaces in 2060 to be equal to 143 million $\mathrm{m}^{2}$ for the service sector and to 498 million $\mathrm{m}^{2}$ for the housing sector. To derive the housing surfaces that are cooled, we cannot apply the percentages from Table 2 to the overall surface projections. Rather, we based our estimations on the annual energy consumption of Swiss households for cooling, which is equal to $0.1 \mathrm{PJ}$ in 2001 according to Kirchner et al. (2010). In this manner, the fully-cooled housing surface in 2000 was 1.5 million $\mathrm{m}^{2}$, which represents a share of $0.6 \%$ of the overall housing surfaces. For 2060, we assume a share of $2 \%$.

\subsection{Incorporating HDD and CDD Changes in a Computable General Equilibrium Model}

We explain in this subsection how the changes in heating and cooling needs are introduced in the equations representing household energy consumption. In GEMINI-E3, energy consumption for residential purposes (heating, cooling, 
cooking, ...) is represented by a nested CES functions that is shown in Figure 2. Energy consumption for residential needs (Hrese) is given by:

$$
\text { Hrese }_{t}=\text { Hres }_{t} \cdot \lambda^{\text {bres }} \cdot \alpha^{\text {hres }} \cdot\left[\frac{\text { Pres }_{t}}{\text { Prese }_{t} \cdot \lambda^{\text {bres }}}\right]^{\sigma_{\text {hres }}} \text {, }
$$

where Hres represents household consumption for residential purposes (i.e. expenses for shelter and energy), Pres and Prese are respectively the price of residential consumption and the price of energy used for residential purposes. $\sigma^{\text {hres }}$, $\alpha^{\text {hres }}$ and $\lambda^{\text {bres }}$ represent the CES parameters, respectively the elasticity of substitution, the share parameter and the technology shifter.

In GEMINI-E3, energy demand for housing is split between fossil fuels and electricity following a CES function. This implies the following demand for fossil fuels:

$$
\text { Hresef }_{t}=\frac{\text { Hrese }_{t} \cdot \lambda^{\text {brese }} \cdot \alpha^{\text {brese }}}{\left(1+\tau_{\text {bresef }}\right)^{t}} \cdot\left[\frac{\text { Prese }_{t}}{\text { Presef }_{t} \cdot \lambda^{\text {brese }} /\left(1+\tau_{\text {bresf }}\right)^{t}}\right]^{\sigma_{\text {hrese }}^{\text {he }}},
$$

where Hresef represents total fossil energy consumption for residential purpose, Presef the price of this energy and $\tau_{\text {bresef }}$ a technical progress associated to this fossil energy. Electricity consumption by households (Hreseel) is given by:

$$
\text { Hreseel }_{t}=\frac{\text { Hrese }_{t} \cdot \lambda^{\text {hrese }} \cdot\left(1-\alpha^{\text {hrese }}\right)}{\left(1+\tau_{\text {bresel }}\right)^{t}} \cdot\left[\frac{\text { Prese }_{t}}{\text { Preseel }_{t} \cdot \lambda^{\text {brese }} /\left(1+\tau_{\text {bresel }}\right)^{t}}\right]^{\sigma_{\text {hroe }}}
$$

The impact of global warming on heating and cooling needs is implemented by adjusting the technical progress coefficients associated with fossil energy and electricity consumption for residential purposes (respectively $\tau_{\text {bresef }}$ and $\tau_{\text {bresel }}$ ). This corresponds to the assumption that the changes in HDD and CDD can be interpreted as changes in the quantities of energy that are needed to attain the same room climate. The result will not only be a reallocation of demand as proposed by Roson, Bosello, and Cian (2007) and Eboli, Parrado, and Roson (2010) but also a direct welfare impact emanating from a change in energy needs. With regard to heating, the technical progress on fossil energy is increased from the business-as-usual (BAU) value based on the share of fossil energy that is used for heating and the ex-ante change in energy consumption for heating, which is equal to the change of HDD. For simplification purposes, we assume that heating 
does not use electricity in our model simulation. According to Prognos (2012) electricity represents around $8 \%$ of energy used for heating in 2010. For cooling, a similar protocol is assumed and the technical progress related to electricity is therefore decreased based on the share of electricity used for cooling and the exante change in electricity consumption for cooling.

In the climate scenarios, we recompute the technical progresses by using the equations 8 and 9 .

$$
\begin{gathered}
\overline{\tau_{\text {bresef }}}=\frac{\tau_{\text {bresef }}}{1+\beta_{\text {bresf }}^{\text {beating }} \cdot\left(\frac{H D D_{2060}}{H D D_{1980-2009}}-1\right)} \\
\overline{\tau_{\text {bresel }}}=\frac{\tau_{\text {hresel }}}{1+\beta_{\text {bresel }}^{\text {cooling }} \cdot\left(\frac{\text { Elec }_{2060}}{\text { Elec }_{1980-2009}}-1\right)}
\end{gathered}
$$

Where $\beta_{\text {bresef }}^{\text {heating }}$ and $\beta_{\text {bresel }}^{\text {cooling }}$ represent respectively the share of fossil energy used for heating and the share of electricity used for cooling. We apply a similar method for heating and cooling in commercial activities and industry.

\section{CH2011 Climate Scenarios}

The impacts of global warming on daily temperatures in Switzerland are derived from the CH2011 initiative (C2SM et al., 2011). This work is a multi-institutional collaboration between the Center for Climate System Modeling, MeteoSwiss, ETH Zurich, the National Centre of Competence in Research on Climate and the Advisory body on climate changes OcCC. Among different products, it provides regionalized daily projections of changes in temperature and precipitation relative to the reference period 1980-2009. Derived from climate scenarios of seasonal means, these daily projections are available for three regions (northeastern Switzerland, western Switzerland, and Switzerland south of the Alps), three 30-year projection periods centered around 2035, 2060 and 2085, three greenhouse gas emission scenarios (RCP3PD, A1B and A2 (IPCC, 2000; IPCC, 2013)) and three estimates ("lower", "medium" and "upper") reflecting the uncertainty arising from both variability by decade and climate models. Considering all Swiss regions, best estimates for the increases of seasonal mean temperature according to the CH2011 initiative are given in Table 3. 
Table 3: "Medium" Estimates of Seasonal Mean Temperature Increase by Climate Scenarios and Time Periods in ${ }^{\circ} \mathrm{C}$

\begin{tabular}{lccc}
\hline & 2035 & 2060 & 2085 \\
\hline A1B & $0.9-1.4^{\circ}$ & $2.0-2.9^{\circ}$ & $2.7-4.1^{\circ}$ \\
A2 & $0.8-1.3^{\circ}$ & $1.9-2.8^{\circ}$ & $3.2-4.8^{\circ}$ \\
RCP3PD & $0.9-1.4^{\circ}$ & $1.2-1.7^{\circ}$ & $1.2-1.8^{\circ}$ \\
\hline
\end{tabular}

Practically, daily average temperatures over the period 1980-2009 were first obtained from 64 meteorological stations located throughout Switzerland. This allowed the computation of indices of HDD and CDD for the reference period. The regionalized daily changes in temperature were then used to modify the daily average temperature for each meteorological station and values of the HDD and CDD indices were derived for 2060. In order to obtain single figures of HDD and CDD, values of the indices at the meteorological station level were aggregated to the Swiss level using the current spatial distribution of the population across the country. This means that the weights derived from this distribution were used to aggregate the indices in both the reference and the projection period.

\subsection{Evolution of the Climatic Indices}

Figure 3 shows the evolution of the HDD and the CDD indicators for the years 2035 and 2060. In the reference period 1980-2009, yearly values of HDD are respectively equal to $3328^{\circ}, 3102^{\circ}, 2836^{\circ}$ for $\theta_{t h}=12^{\circ}, \theta_{t h}=10^{\circ}$ and $\theta_{t h}=8^{\circ}$. In 2060, the HDD will decrease by between $5.4 \%$ and $32.7 \%$ relative to the reference period, depending on the climatic scenario and the threshold temperature $\left(\theta_{t h}\right)$ used. The scenarios A1B and A2 give similar results because the global GHG emissions profiles are close for the period 2010-2060 (IPCC, 2000). The RCP3PD scenario, which assumes that global warming will be limited to $2^{\circ} \mathrm{C}$, reduces the decrease of HDD by more than $40 \%$ with respect to the other two scenarios. Within the same climatic scenario, the HDD decrease is multiplied by more than a factor of 2 when we move from the lower estimate to the upper estimate.

In contrast to heating, space cooling needs will increase with climate change as indicated by $\mathrm{CDD}$ changes. The percentage changes of $\mathrm{CDD}$ are much bigger in comparison to the HDD, which comes of course from the fact that in Switzerland the CDD for the reference period are quite low. Using equation 2, it is for instance equal to $45^{\circ}$ when $\theta_{b p}=18.3^{\circ}$ and to $7^{\circ}$ when $\theta_{b p}=20^{\circ}$. Again, the 
Figure 3: $\mathrm{HDD}$ with $\theta_{t h}=12^{\circ} \mathrm{C}$ (top) and $\mathrm{CDD}$ with $\theta_{b p}=18.3^{\circ} \mathrm{C}$ (bottom)
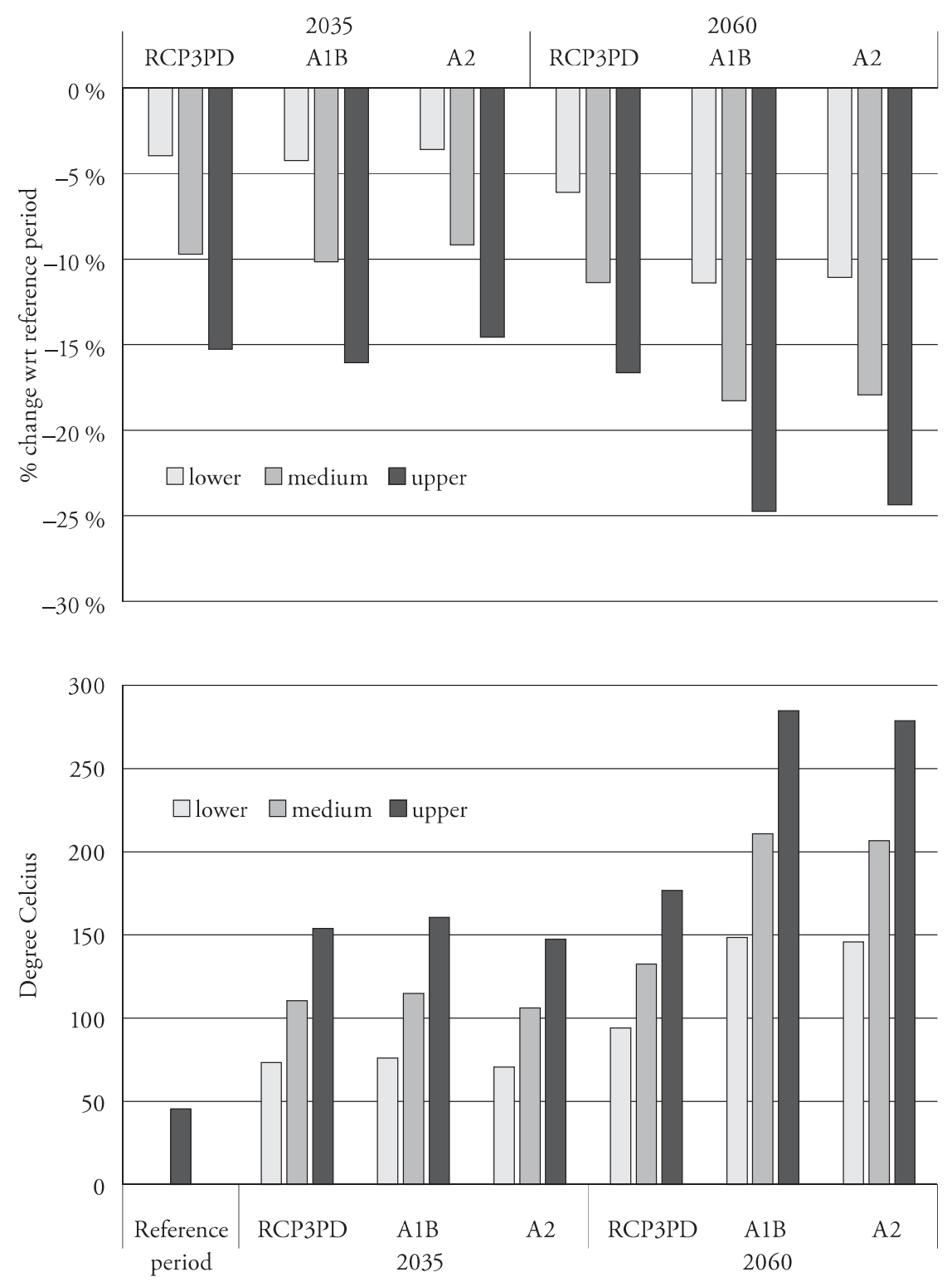

Swiss Journal of Economics and Statistics, 2017, Vol. 153 (4) 
percentage changes of scenarios A1B are similar to those of scenario A2. Within the same scenario, the climate uncertainty (represented by the lower, medium and upper estimates) significantly affects the percentage changes. For example, in scenario $\mathrm{A} 1 \mathrm{~B}$, the CDD increase in 2060 within a range of $227 \%$ to $527 \%$ with $\theta_{b p}=18.3^{\circ}$. However as it was noted in the previous subsection, in contrast to heating, the changes in cooling needs are not assumed to be proportional to the variations of CDD (see equation 3).

\subsection{The Business-as-Usual Scenario}

To simulate the evolution of the economy until 2060, the model uses predictions of population and GDP growth. The study employs population forecasts from the World Population Prospect (United Nations and Social Affairs, 2011). Future GDP growth rates are from the Swiss State Secretariat for Economic Affairs for Switzerland and the World Energy Outlook published by International Energy Agency (2013b) for all other countries. Swiss economic growth is predicted to be 0.7 percent per year until 2030 before slowing to about 0.5 percent per year until 2060.

Assumptions concerning energy prices are drawn from the World Energy Outlook using the current policies scenario. As the predictions by the International Energy Agency stop in 2035, we assume that the energy prices will continue to slowly increase after that date. The oil price is assumed to reach $174 \mathrm{USD}$ per barrel in 2060 and the price of imported gas in Europe 16.8 USD per MBtu (both in 2012 prices).

As our study focuses on the Swiss energy sector, we only describe the Swiss figures. Increased cooling implies increased electricity demand. This will happen at a time when the electricity generation mix changes fundamentally. One important assumption concerning the future configuration of the Swiss energy sector is related to the decision on nuclear power. In May 2011, after the devastating earthquake in Japan and the disaster at Fukushima, the central executive power - the Federal Council - decided to gradually decommission all nuclear power plants until a complete phase out by 2034. Based on this decision, BundesAMT FÜr ENERGIE BFE (2011) gives the life of operation for the five existing nuclear power plants which are all introduced in GEMINI-E3. Electricity generation in Switzerland is currently made up of around $53 \%$ hydroelectric power and $41 \%$ nuclear power with the remaining $6 \%$ shared between various other production methods, including waste incineration and other renewables. Figure 4 shows the evolution of Swiss electricity generation over the period 2010-2060. Total electricity production remains more or less constant over the time horizon for three main reasons: 
- growth of the economy is very low over the period;

- we assume an autonomous energy efficient improvement (AEEI) (AzAR and Dowlatabadi, 1999) of $1.5 \%$ per year;

- the replacement of nuclear power plants by more costly technologies increases the electricity prices and limits the penetration of electricity.

Figure 4: Electricity Generation in Switzerland in TWh

(2011 IEA: International Energy Agency, 2013a)

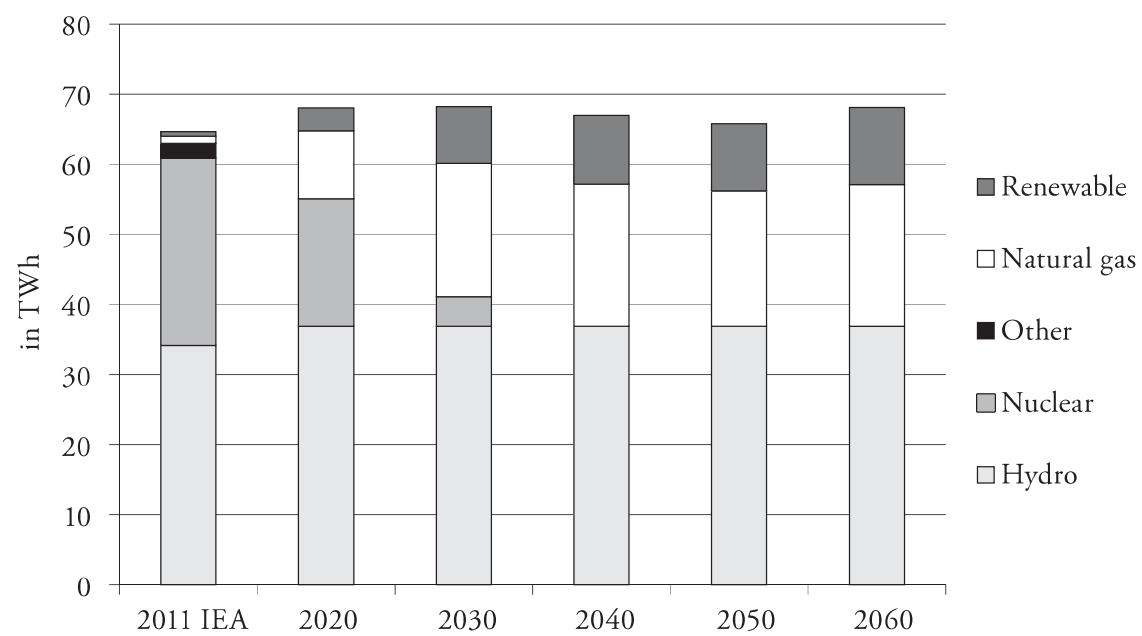

The evolution of the electricity mix is driven by the retirement of nuclear power plants and by the assumption that no new hydraulic sites are available in Switzerland; hydraulic power generation is thus flat. In the first period of the simulation (2010-2030), nuclear capacities are mainly replaced by natural gas power plants and to a lesser extent by renewables. In the second half of the scenario time horizon, as the technology of solar photovoltaic becomes increasingly competitive, it is deployed on a large scale and the share of renewables (including hydro) reaches $66 \%$ by 2060 . Also of relevance to our impact study is the ratio of electricity price to petroleum products price and its evolution until 2060; it decreases between 2010 and 2060 by $30 \%$ in Switzerland. Swiss non-electricity energy consumption remains dominated by petroleum products, whose consumption increases annually by $0.6 \%$ and represents in 2060 around $80 \%$ of fossil energy consumption. The consumption of natural gas increases by $0.7 \%$ per year, mainly driven by the generation of electricity with gas power plants. 


\section{The Impacts of Climate Change on Heating and Cooling Energy Demands}

\subsection{The Climate Change Scenarios}

We investigate the economic impacts of global warming on energy consumption for both heating and cooling. These changes, which mainly rely on the evolution of two climatic indices, were derived in the previous section. First, we focus our analysis on the $\mathrm{A} 1 \mathrm{~B}$ scenario with the "medium" estimate and we select $\theta_{t h}=12^{\circ}$ and $\theta_{b p}=18.3^{\circ}$, the thresholds for heating and cooling usually retained for the Swiss case (WINKLER et al., 2014) ${ }^{7}$. We shall perform a sensitivity analysis at the end of this section.

Climate warming following the A1B scenario leads to a potential or ex-ante decrease in fossil energy needed to obtain the same thermal comfort in all buildings by an average of $18.3 \%$ in 2060 . We retain this rate for all sectors. This corresponds to a decrease in fossil energy need for housing by $15.9 \%$, considering that about $87 \%$ of fossil energy consumption related to housing is for room heating, the remainder being used for other purposes such as water heating. In contrast to heating, the ex-ante increase in the energy consumption for cooling is sector specific with values set at $0.6 \mathrm{TWh}$ for the housing sector and at $1.4 \mathrm{TWh}$ for the service sector in 2060. We introduce these changes on heating and cooling into the model sequentially, in order to distinguish their economic effects. This leads to simulate 8 scenarios, summarized below:

1. reduction in heating energy need, for constant comfort, in housing;

2. reduction in heating energy need, for constant output, in services;

3. reduction in heating energy need, for constant output, in industry;

4. reduction in heating energy need, for constant activity, in all sectors;

5. increase in cooling energy need, for constant comfort, in housing;

6. increase in cooling energy need, for constant output, in services;

7. increase in cooling energy need, for constant output, in housing and services;

8. reduction in heating and increase in cooling energy need, for constant activity, in all sectors.

The first scenario deviates from the business-as-usual (BAU) scenario by accelerating the rate of energy efficiency improvement in room heating for households

7 It is worth noting that the values of projected future temperature change for the "medium" estimate of the A1B scenario are always higher in summer than in winter (C2SM et al., 2011, p.79).

Swiss Journal of Economics and Statistics, 2017, Vol. 153 (4) 
in such a way that they could lower their fossil energy consumption related to housing by $15.9 \%$ by 2060 and still obtain the same comfort. This exogenous change triggers a number of adjustments simulated by the model with the effect that the actual or ex-post decrease in energy consumption related to housing in 2060 is only $10.4 \%$. This implies a rebound effect of $35 \%$.

These effects are well documented in the economic literature (DimitropouLOS, 2007), which explains that when the cost of energy services falls (which is the case when less energy is required to satisfy the same level of comfort) there is a tendency to increase the level of comfort (i.e. increase the temperature inside buildings) by using more energy. This, in turn, limits the fall in the initial calculation of change in energy demand. By regressing energy use for space heating on HDD, Duerinck, Renders, and Schoeters (2008) found an elasticity of 0.55 on average for selected European Union member states. This corresponds to a potential rebound effect of $45 \%$. For Switzerland, using a similar econometric approach, WinkLer et al. (2014) found a rebound effect equal to $50 \%$.

However these studies focused on the "direct" effect. Allan et al. (2007) noted that CGE models also account for the "indirect" and "economy-wide" effects that pass through changes in outputs, income and relative prices. Indirect effects, also called "secondary effects" (Greening, Greene, and Difiglio, 2000) result from an increase in demand for other goods including other energy goods driven mainly by an income effect. "Economy-wide effects" proceed from price and quantity changes within the economy, which concern not only the energy industry, but all other sectors as well. In an open economy these effects also reflect changes in competitiveness. Greening, GreEne, and Difiglio (2000) remarked that only a general equilibrium analysis can predict the ultimate result of all these changes. This decomposition has often been performed to analyze the rebound effect of energy efficiency improvements. Allan et al. (2007) applied this general equilibrium analysis to industry energy use, and LeCCA et al. (2014) to household energy use.

As indicated above, the decrease in fossil energy needed to keep the same room climate for households in the A1B scenario as in the BAU corresponds to $18.3 \%$ of the heating energy they need or $15.9 \%$ of their fossil energy consumption in housing by 2060. Scaled up to the full economy, this would allow for an ex-ante decrease of oil consumption by $4.6 \%$ and of gas consumption by $3.5 \%$ in 2060 . In fact, our simulations show that national oil consumption decreases only by $3.1 \%$ and gas consumption by $1.3 \%$. This implies economy-wide rebound effects of $32 \%$ and $62 \%$ for oil and gas respectively. Indeed, the savings for heating energy allow households to boost their consumption for other products by $0.7 \%$. This entails also an increase in electricity consumption by $1.0 \%$, which is partly produced with natural gas. 
Table 4: Impacts of a Climate Change Induced Reduction in Heating Energy Consumption in 2060 (climate scenario A1B, \% change with respect to the BAU scenario)

\begin{tabular}{lcccc}
\hline & $\begin{array}{c}\text { Housing } \\
\text { (scenario 1) }\end{array}$ & $\begin{array}{c}\text { Services } \\
(\text { scenario 2) }\end{array}$ & $\begin{array}{c}\text { Industry } \\
(\text { scenario 3) }\end{array}$ & $\begin{array}{c}\text { All sectors } \\
\text { (scenario 4) }\end{array}$ \\
\hline Total energy consumption & & & & \\
$\quad$ Petroleum products & $-3.1 \%$ & $-1.6 \%$ & $-0.1 \%$ & $-4.8 \%$ \\
$\quad$ Natural gas & $-1.3 \%$ & $-1.0 \%$ & $-0.2 \%$ & $-2.5 \%$ \\
$\quad$ Electricity & $1.0 \%$ & $-0.3 \%$ & $0.0 \%$ & $0.6 \%$ \\
\hline $\mathrm{CO}_{2}$ emissions & $-2.8 \%$ & $-1.4 \%$ & $-0.1 \%$ & $-4.3 \%$ \\
Welfare change in Mio USD & 644 & 177 & 34 & 855 \\
As a \% of consumption & $0.14 \%$ & $0.04 \%$ & $0.01 \%$ & $0.18 \%$ \\
\hline
\end{tabular}

At the aggregate level, the scenario results in large welfare gains of 644 million USD. The effect on the environment is also positive, since $\mathrm{CO}_{2}$ emissions are reduced by $2.8 \%$ in 2060 relative to BAU scenario.

In the service sector, a climate change induced reduction in heating energy consumption (scenario 2) results in smaller decreases of fossil fuel consumption in 2060 , by $-1.6 \%$ for petroleum products and by $-1 \%$ for natural gas. In this case, the Swiss economy benefits from reduced production costs in the service sector and the aggregate welfare gain is evaluated to amount to 177 million USD. In addition to the economic gains, $\mathrm{CO}_{2}$ emissions are reduced by $1.4 \%$ in 2060. With regard to the industry sector, reduced energy consumption for heating (scenario 3) affects its overall consumption of fossil fuels only slightly. This is due to the fact that heating only accounts for a small part of this sector's energy use. The reduced production costs, though smaller than in the service sector, decrease prices and also contribute to making the Swiss economy more competitive, thereby generating a welfare gain of 34 million USD.

When taking into account the impacts on the three sectors simultaneously (scenario 4), the welfare gain amounts to 855 million USD, which corresponds to the sum of the welfare gains derived for the first three scenarios.

With respect to cooling, the increase in electricity consumption has detrimental effects on the Swiss economy but they are quite small. Looking first at its impact on the housing sector (scenario 5), the ex-ante change on household electricity consumption is an increase of $2.1 \%$ in 2060. Ex-post, we find that household consumption of electricity increases only by $1.6 \%$ in 2060 , which raises the overall consumption of electricity in Switzerland by $0.6 \%$. This increase is 
covered by more electricity production from both thermal power plants fueled with natural gas and renewables ( $2 / 3$ from natural gas and $1 / 3$ from renewables in 2060). This is the reason for the $0.6 \%$ increase in natural gas consumption reported in Table 5. Though moderate, higher expenditures for cooling also divert households from consuming petroleum products $(-0.1 \%)$. Therefore, the net effect on $\mathrm{CO}_{2}$ emissions is only slightly detrimental with a $0.04 \%$ increase. At the aggregate level, welfare losses amount to 53 million USD. The impacts of higher cooling needs are larger for the service sector (scenario 6). In this case, the Swiss consumption of electricity is raised by $1.5 \%$, resulting in a higher level of natural gas consumption for electricity production. The welfare cost is estimated to be equal to 66 million USD. The combined effects of increasing cooling energy needs in housing and services (scenario 7) is quite close to the sum of their separate effects (see Table 5).

Table 5: Impacts of a Climate Change Induced Increase in Cooling Electricity Consumption in 2060 (climate scenario A1B, \% change with respect to the BAU scenario)

\begin{tabular}{lccc}
\hline & $\begin{array}{c}\text { Housing } \\
(\text { scenario 5) }\end{array}$ & $\begin{array}{c}\text { Services } \\
(\text { scenario 6) }\end{array}$ & $\begin{array}{c}\text { All sectors } \\
\text { (scenario 7) }\end{array}$ \\
\hline Total energy consumption & & & \\
$\quad$ Petroleum products & $-0.1 \%$ & $0.1 \%$ & $0.0 \%$ \\
$\quad$ Natural gas & $0.6 \%$ & $1.6 \%$ & $2.2 \%$ \\
Electricity & $0.6 \%$ & $1.5 \%$ & $2.1 \%$ \\
\hline $\mathrm{CO}_{2}$ emissions & $0.04 \%$ & $0.35 \%$ & $0.39 \%$ \\
Welfare change in Mio USD 2010 & -53 & -66 & -127 \\
As a \% of consumption & $-0.01 \%$ & $-0.01 \%$ & $-0.03 \%$ \\
\hline
\end{tabular}

Finally, Table 6 presents the combined effects of higher energy requirements for cooling and lower energy requirements for heating (scenario 8). The aggregated welfare impact is predicted to be positive and equal to 733 million USD in 2060. 
Table 6: Impacts of Climate Change Induced Variations in both Heating and Cooling Energy Needs in 2060 (climate scenario A1B, $\%$ change with respect to the BAU scenario)

\begin{tabular}{lc}
\hline & $\begin{array}{c}\text { All sectors } \\
\text { (scenario 8) }\end{array}$ \\
\hline Total energy consumption & \\
\hline Petroleum products & $-4.8 \%$ \\
Natural gas & $-0.3 \%$ \\
Electricity & $2.8 \%$ \\
\hline $\mathrm{CO}_{2}$ emissions & $-3.9 \%$ \\
Welfare change in Mio USD & \\
As a $\%$ of consumption & 733 \\
\hline
\end{tabular}

\subsection{A Sensitivity Analysis}

We simulate the climate change scenarios for the two GHG emissions profiles (RCP3PD and $\mathrm{A} 1 \mathrm{~B})$ and the three associated estimates corresponding to the $95 \%$ confidence interval ${ }^{8}$. Figure 5 shows the spread of the welfare change in 2060. Scenario RCP3PD limits global warming and the impacts on Swiss energy consumption relative to scenario A1B. It is interesting to note that the upper (lower) estimates correspond roughly to the same percentage changes with respect to the medium estimates in the two scenarios.

Finally, we perform some sensitivity analysis on the cooling scenarios. Indeed, there are uncertainties relative to the diffusion (purchase) of air-conditioning systems in Switzerland and to the impact of global warming on this diffusion. The installation of air-conditioning is currently tightly regulated. This regulation could be loosened if heat waves become more frequent. The scenario presented in the previous subsection assumes that diffusion will increase with temperature increases. We have simulated three new scenarios:

- a "low" scenario, where we assume no effect of global warming on the diffusion of air-conditioning systems; this assumption is retained for example by LABRIET et al. (2015);

8 The authors of these scenarios emphasize that these confidence intervals should not be interpreted in a strictly probabilistic way. 
Figure 5: Welfare Change in 2060 Relative to the BAU Scenario for Qualitative $95 \%$ Confidence Intervals of the RCP3PD and A1B Scenarios, in Mio USD ${ }_{2010}$

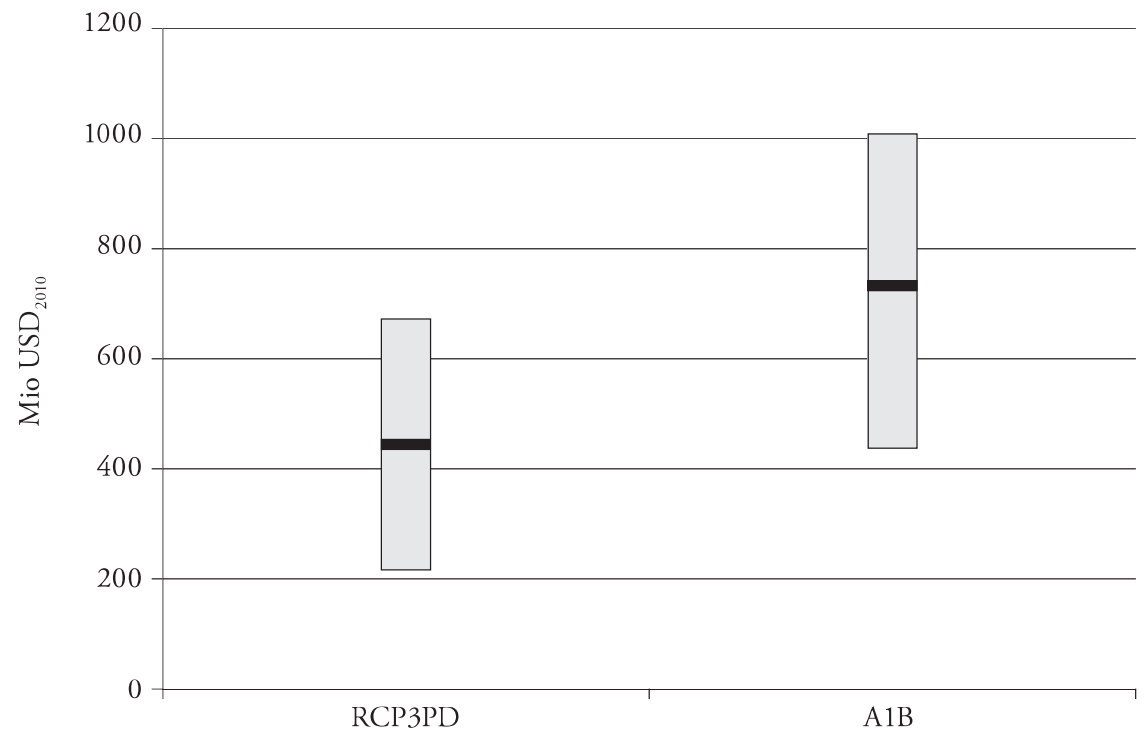

- a "high" scenario, where we increase the percentage of surface cooled with respect to the hypothesis used in the previous subsection;

- a "very high" scenario, where we assume that $100 \%$ of surfaces will be cooled in services and that $20 \%$ of residential surfaces will be cooled.

Table 7 summarizes the scenario assumptions that we use for the year 2060 . Figure 6 shows the changes in electricity consumption and the welfare impacts of these different assumptions under the scenario A1B with a medium estimate. In the "very high" scenario for the diffusion of air-conditioning systems, electricity consumption increases significantly by $6.2 \%$. In this scenario, the negative impact on welfare reaches 407 million USD, but the aggregated impact taking into account the positive impact on heating remains positive and equal to 448 million USD. Note that the differences in housing comfort with more or less cooling are not taken into account in these welfare assessments. If they were, the scenarios with greater penetration of air-conditioning would look much better. 
Figure 6: Electricity Consumption Changes in \% (top) and Welfare Change in Mio USD 2010 (bottom) under Climate Scenario A1B with Respect to the BAU Scenario in Year 2060 for Different Assumptions on Cooling Equipment Diffusion

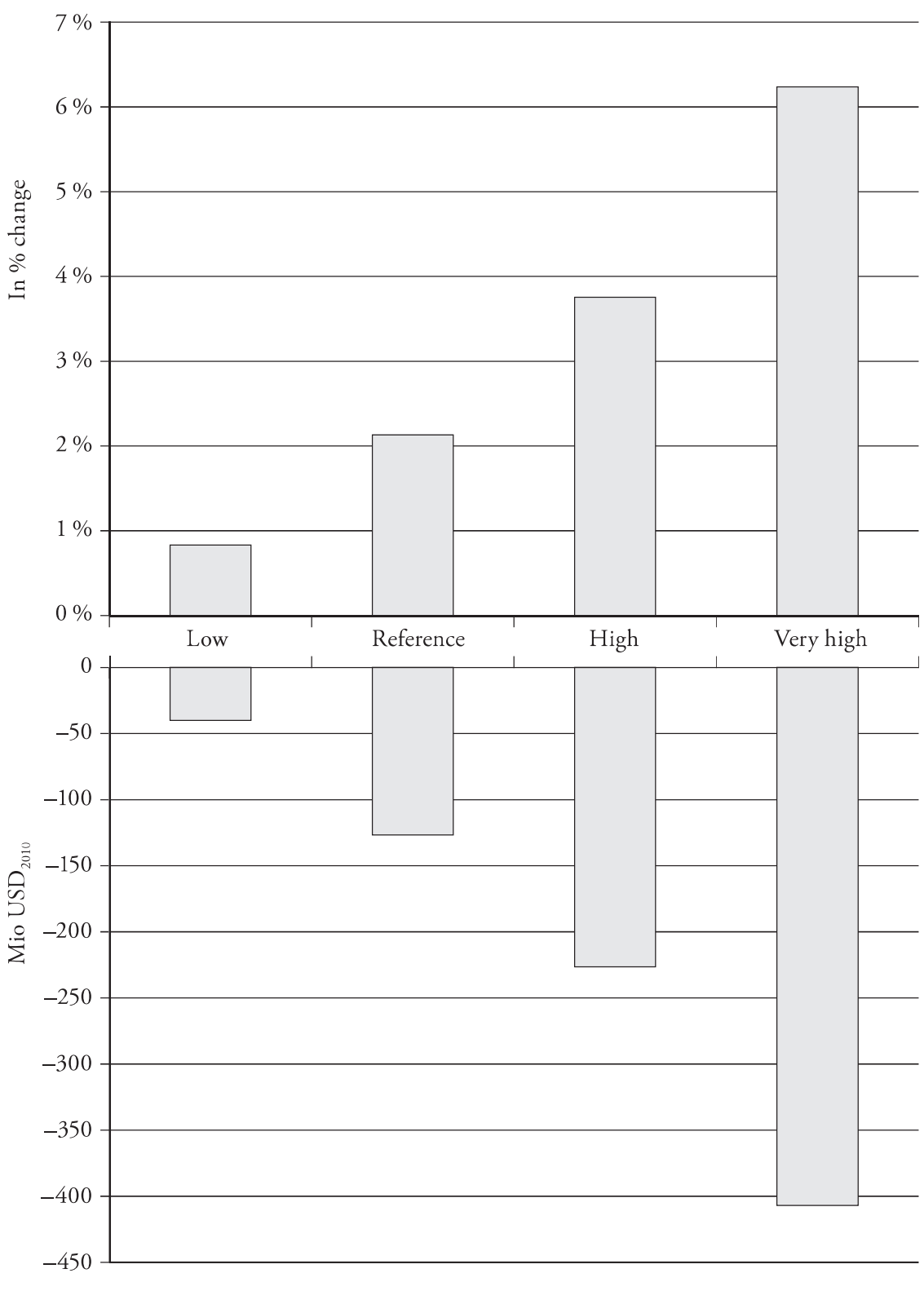

Swiss Journal of Economics and Statistics, 2017, Vol. 153 (4) 
Table 7: Assumptions on Cooled Surfaces in 2060

\begin{tabular}{lcccc}
\hline & Low & Reference & High & Very high \\
\hline Services \% of space cooled & & & & \\
Not cooled & $30 \%$ & $15 \%$ & $5 \%$ & $0 \%$ \\
Partially cooled & $40 \%$ & $35 \%$ & $20 \%$ & $0 \%$ \\
Fully cooled & $30 \%$ & $50 \%$ & $75 \%$ & $100 \%$ \\
\hline Residential \% of surface cooled & $1.1 \%$ & $5 \%$ & $10 \%$ & $20 \%$ \\
\hline
\end{tabular}

\section{Conclusion}

Our aim with this paper has been to analyze the multiple repercussions of changed heating and cooling bills, both for households and businesses, brought about by climate warming. This was done for the Swiss economy with the help of a computable general equilibrium model, which allowed us to take into account both direct and a large range of indirect rebound effects. We found significant positive welfare gains, mainly from the fact that the income that is no longer spent for imported fossil fuels is used by households to expand their consumption of other goods and services. This effect is strengthened by the reduction in production costs in the industry and service sectors. These two effects largely outweigh the negative effects of increased electricity bills for cooling. However, this result is sensitive to the assumptions about the penetration of air conditioning in housing, from which it is currently essentially banned. A $20 \%$ penetration rate would suffice to divide the welfare gain in two. This suggests that if the method could be applied to any other country, the numeric results could be quite different for a much warmer country. Nevertheless, our results are consistent with those obtained in earlier studies carried out either for Switzerland or for countries with comparable climatic conditions (Aebischer et al., 2007; Seljom et al., 2011; KranzL et al., 2015). Our analysis also sheds light on the magnitude of rebound effects, which offset a significant part of the reduction in energy consumption and $\mathrm{CO}_{2}$ emissions, which reduced heating needs would otherwise make possible. Particularly the net impact on $\mathrm{CO}_{2}$ emissions of a warmer climate depends on how additional electricity used for cooling is produced (with natural gas and renewables in our simulations). In other countries, where electric heating is permitted, the electricity savings for milder winter could offset the additional electricity needed for cooling. 
Our results rely on the most up-to-date climate change scenarios available for Switzerland (the Swiss Climate Change Scenarios CH2011), which are based on a new generation of climate models with higher resolution, improved statistical methods, and an account of all recent relevant studies.

Our analysis has focused on the impacts of climate change on the energy needed for maintaining comfortable thermal conditions in buildings. This is only a small part of the possible effects of a changed climate, so our results should not be interpreted in the sense that climate change could be favorable for Switzerland or any comparable country. For instance, climate change will have a negative welfare impact in the future due to the loss of thermal comfort for those people still living in buildings without air-conditioning. Further research should take into account the fact that climate change will trigger more investments in cooling facilities and these additional investments are not implemented in the simulations reported in this paper. Their integration into the analysis would result in smaller welfare gains. On the other hand, one should take into account the impacts of warmer temperatures on building designs and refurbishments. Indeed, warmer winters also imply less need for thermal insulation, which would boost welfare gains.

The paper shows by how much energy consumption declines due to global warming. This reduces the attractiveness of building insulation. Assessing policies promoting the thermal insulation of buildings without taking this into account would overestimate the welfare gains from these policies (or underestimate their costs). On the other hand, ignoring the energy savings made possible by a warmer climate leads to underestimating welfare improvements. Eventually, further research might include the positive welfare impacts of air-conditioning on health, which mitigates mortality and morbidity during heat waves.

\section{References}

Aebischer, Bernard, Giacomo Catenazzi, George Henderson, and Martin Jаков (2007), "Impact of Climate Change on Thermal Comfort, Heating and Cooling Energy Demand in Europe", in Saving Energy - Just Do It!', European Council for an Energy Efficient Economy ECEEE.

Allan, Grant, Nick Hanley, Peter Mc Gregor, Kim Swales, and Karen Turner (2007), "The Impact of Increased Efficiency in the Industrial Use of Energy: A Computable General Equilibrium Analysis for the United Kingdom", Energy Economics, 29(4), pp.779-798. 
Armington, Paul S. (1969), "A Theory of Demand for Products Distinguished by Place of Production", IMF Staff Papers, 16, pp. 159-178.

Auffhammer, Maximilian, and Erin T. Mansur (2014), "Measuring Climatic Impacts on Energy Consumption: A Review of the Empirical Literature", Energy Economics, 46(0), pp. 522-530.

Azar, Christian, and Hadi Dowlatabadi (1999), "A Review of Technical Change in Assessment of Climate Policy", Annual Review of Energy and the Environment, 24(1), pp. 513-544.

Bernard, A., and M. Vielle (2008), "GEMINI-E3, A General Equilibrium Model of International-National Interactions between Economy, Energy and the Environment”, Computational Management Science, 5(3), pp. 173-206.

Bundesamt Für ENergie BFE (2011), "Grundlagen für die Energiestrategie des Bundesrates; Frühjahr 2011, Aktualisierung des Energieperpektiven 2035", Tech. rep., Schweizerische Eidgenossenschaft.

C2SM, MeteoSwiss, ETH, NCCR Climate, and OcCC (2011), Swiss Climate Change Scenarios CH2011, Zurich.

Christenson, M., H. Manz, and D. Gyalistras (2006), "Climate Warming Impact on Degree-Days and Building Energy Demand in Switzerland", Energy Conversion and Management, 47, pp. 671-686.

Ciscar, Juan-Carlos, and Paul Dowling (2014), "Integrated Assessment of Climate Impacts and Adaptation in the Energy Sector", Energy Economics, 46, pp. 531-538.

Craig, Robin Kundis (2011), "Energy System Impact", Tech. rep., FSU College of Law, Public Law Research Paper No. 503.

De Cian, Enrica, Elisa Lanzi, and Roberto Roson (2013), "Seasonal Temperature Variations and Energy Demand", Climatic Change, 116(3-4), pp. 805-825.

Dimaranan, B. V. (2006), Global Trade, Assistance, and Production: The GTAP 6 Data Base, Center for Global Trade Analysis, Purdue University: Center for Global Trade Analysis Purdue University.

Dimitropoulos, John (2007), "Energy Productivity Improvements and the Rebound Effect: An Overview of the State of Knowledge", Energy Policy, 35(12), pp. 6354-6363.

Duerinck, J., N. Renders, and K. Schoeters (2008), "Assessment and Improvement of Methodologies used for Greenhouse Gas Projection", Tech. rep., Vlaamse Instelling voor Technologisch Onderzoek.

Eboli, Fabio, Ramiro Parrado, and Roberto Roson (2010), "Climate-Change Feedback on Economic Growth: Explorations with a Dynamic General Equilibrium Model", Environment and Development Economics, 15, pp. 515-533. 
Faust, Anne-Kathrin, Camille Gonseth, and Marc Vielle (2015), "The Economic Impact of Climate Driven Changes in Water Availability in Switzerland", Water Policy, 17(5), pp. 848-864.

Frank, TH. (2005), "Climate Change Impacts on Building Heating and Cooling Energy Demand in Switzerland", Energy and Buildings, 37(11), pp. 1175-1185.

Greening, Lorna A., David L. Greene, and Carmen Difiglio (2000), "Energy Efficiency and Consumption - the Rebound Effect - a Survey", Energy Policy, 28(67), pp. 389-401.

Hamududu, B., and A. Killingtveit (2012), "Assessing Climate Change Impacts on Global Hydropower", Energies, 5, pp. 305-322.

Howell, Ronald H., Harry J. Sauer, and William J. Coad (2005), Principles of Heating, Ventilating, and Air Conditioning, Atlanta, GA.: American Society of Heating, Refrigerating and Air-Conditioning Engineers.

International Energy Agency (2013a), Energy Balances of OECD Countries, Paris: OECD/IEA.

International Energy Agency (2013b), World Energy Outlook 2013.

IPCC (2000), Special Report on Emissions Scenarios, Cambridge University Press.

IPCC (2013), Climate Change 2013: The Physical Science Basis. Contribution of Working Group I of the Fifth Assessment, Cambridge, UK, and New York, NY, USA: Cambridge University Press.

Joshi, Santosh, Marc Vielle, Frédéric Babonneau, Neil Edwards, and Phil Holden (2016), "Physical and economic consequences of sea-level rise: A coupled GIS and CGE analysis under uncertainties", Environmental and Resource Economics, 65(4), pp. 813-839.

Kirchner, Almut, Andreas Kemmler, Peter Hofer, Mario Keller, Martin Jaков, and Giacomo Catenazzi (2010), „Analyse des schweizerischen Energieverbrauchs 2000-2009 nach Verwendungszwecken“", Tech. rep., Bundesamt für Energie BFE.

Kranzl, Lukas, Marcus Hummel, Wolfgang Loibl, Andreas Müller, Irene Schicker, Agne Toleikyte, Gabriel Bachner, and Birgit BedNar-Friedl (2015), Economic Evaluation of Climate Change Impacts, Development of a Cross-Sectoral Framework and Results for Austria, chapter "Buildings: Heating and Cooling", pp. 235-255, Springer.

Labriet, Maryse, Santosh R. Joshi, Marc Vielle, Philip B. Holden, Neil R. Edwards, Amit Kanudia, Richard Loulou, and Frédéric BabonNEAU (2015), "Worldwide Impacts of Climate Change on Energy for Heating and Cooling", Mitigation and Adaptation Strategies for Global Change, 20(7), pp. 1111-1136. 
Lecca, Patrizio, Peter G. McGregor, J. Kim Swales, and Karen Turner (2014), "The Added Value from a General Equilibrium Analysis of Increased Efficiency in Household Energy Use", Ecological Economics, 100(0), pp. 51-62.

Lehner, B., G. Czisch, and S. Vassolo (2005), "The Impact of Global Change on the Hydropower Potential of Europe: A Model-Based Analysis", Energy Policy, 33(7), pp. 839-855.

Linnerud, K., T. K. Mideksa, and G. S. Eskeland (2011), "The Impact of Climate Change on Nuclear Power Supply", The Energy Journal, 32(1), pp. 149-168.

Nathani, C., D. Sutter, R. van Nieuwroop, M. Peter, S. Kraner, M. HolZhey, H. RütTer, and R. Zandonella (2011), "Energy Related Disaggregation of the Swiss Input-Output Table", Tech. rep., SFOE, EWG Publication, Bern.

OcCC and ProClim (2007), "Climate Change and Switzerland 2050: Expected Impacts on Environment, Society and Economy", Tech. rep., Organe consultatif sur les changements climatiques.

OECD (2015), "The Economic Consequences of Climate Change", Tech. rep., OECD Publishing, Paris.

Prognos (2012), „Die Energieperspektiven für die Schweiz bis 2050 - Energienachfrage und Elektrizitätsangebot in der Schweiz 2000-2050", Tech. rep., Study commissioned by the Swiss Federal Office of Energy, Basel.

Roson, Roberto, Francesco Bosello, and Enrica De Cian (2007), "Climate Change, Energy Demand and Market Power in a General Equilibrium Model of the World Economy", Working Papers 2007.71, Fondazione Eni Enrico Mattei.

Rübbelke, D., and S. VöGele (2011), "Impacts of Climate Change on European Critical Infrastructures: The Case of the Power Sector", Environmental Science \& Policy, 14(1), 53-63.

Seljom, Pernille, Eva Rosenberg, Audun Fidje, Jan Erik Haugen, Michaela Meir, John Rekstad, and Thore Jarlset (2011), "Modelling the Effects of Climate Change on the Energy System - a Case Study of Norway", Energy Policy, 39(11), pp.7310-7321.

United Nations, Department of Economics and Population, Division Social Affairs (2011), "World Population Prospects: The 2010 Revision", Tech. rep.

Wing, IAN Sue (2006), "The Synthesis of Bottom-Up and Top-Down Approaches to Climate Policy: Electric Power Technologies and the Cost of Limiting US $\mathrm{CO}_{2}$ Emissions", Energy Policy, 34, pp. 3847-3869. 
Winkler, R., C. Almer, C. Bader, C. Gonseth, J. Laurent-Luchetti, P. Thalmann, and M. VIelle (2014), CH2014 - Impact, Toward Quantitative Scenarios of Climate Change Impacts in Switzerland, chapter "Energy Consumption of Buildings - Direct Impacts of a Warming Climate and Rebound Effects", pp.99-105, OCCR, FOEN, MeteoSwiss, C2SM, Agroscope and ProClim. 